\title{
Increased attractiveness of honeybee hive product volatiles to adult small hive beetle, Aethina tumida, resulting from small hive beetle larval infestation
}

\author{
R. Andrew Hayes ${ }^{1,2 *}$, Steven J. Rice ${ }^{1}$, Brogan A. Amos ${ }^{1}$ \& Diana M. Leemon ${ }^{1}$ \\ ${ }^{1}$ Department of Agriculture and Fisheries, Agri-Science Queensland, GPO Box 267, Brisbane, Queensland 4001, Australia, \\ and ${ }^{2}$ Forest Industries Research Centre, University of the Sunshine Coast, Sippy Downs, Queensland, Australia \\ Accepted: 12 March 2015
}

Key words: Kodamaea ohmeri, yeast, GC-MS, Coleoptera, Nitidulidae, invasive pest, Apis mellifera, Ascomycota, fermentation, slime, Hymenoptera, Apidae

\begin{abstract}
The small hive beetle, Aethina tumida Murray (Coleoptera: Nitidulidae), is a recent but significant pest of honeybee [Apis mellifera L. (Hymenoptera: Apidae)] hives in various regions throughout the world, including Eastern Australia. The larval stage of this beetle damages hives when they feed on brood, pollen, and honeycomb, leaving behind fermented wastes. In cases of extreme damage, hives collapse and are turned to an odorous mass of larvae in fermenting hive products. The yeast Kodamaea ohmeri (Etchells \& Bell) Yamada et al. (Ascomycota) has been consistently isolated from the fermenting material as well as each life stage of this beetle. Various studies have noted that the small hive beetle is attracted to volatiles from hive products and those of the yeast $K$. ohmeri, although earlier studies have not used naturally occurring hive products as their source of fermentation. This study investigated changes through time in the attractiveness of natural honeybee hive products to the small hive beetle as the hive products were altered by the action of beetle larvae and fermentation by $K$. ohmeri. We used gas chromatography-mass spectrometry and choice-test behavioural assays to investigate these changes using products sampled from three apiaries. Attractiveness of the fermenting hive products ('slime') increased as fermentation progressed, and volatile profiles became more complex. Fermenting hive products remained extremely attractive for more than 30 days, significantly longer than previous reports. These results have strong implications for the development of an external attractant trap to assist in the management of this invasive pest.
\end{abstract}

\section{Introduction}

The small hive beetle (SHB), Aethina tumida Murray (Coleoptera: Nitidulidae), is a pest of European honeybees, Apis mellifera L. (Hymenoptera: Apidae) (Murray, 1867). The beetle is native to sub-Saharan Africa where it is a minor pest of little economic importance restricted to infesting weak, stressed or diseased African honeybee colonies (Lundie, 1940; Neumann \& Elzen, 2004; Ellis \& Hepburn, 2006). Outside of its native Africa, SHB has proven to be far more destructive. SHB was first reported from Florida, USA, in 1998 (Elzen et al., 1999), and by 2004 had spread widely throughout the USA and was

*Correspondence: R.A. Hayes, Agri-Science Queensland, Department of Agriculture and Fisheries, GPO Box 267, Brisbane, Queensland 4001, Australia. E-mail: andrew.hayes@daf.qld.gov.au estimated to be causing US\$3 million annually in losses to the beekeeping industry (Hood, 2004). This beetle has since established in Australia (Gillespie et al., 2003; Neumann et al., 2010) and been detected in Egypt (Mostafa \& Williams, 2002; Hassan \& Neumann, 2008), Portugal (Ritter, 2004), and Canada (Clay, 2006). In Australia, SHB was first reported from an apiary in Richmond, New South Wales (Somerville, 2003). By 2011 it had spread along the east coast of Australia from Mareeba in the north to the Melbourne CBD in the south (Lamb \& Leemon, 2011). The destructive potential of SHB in Australia was realized once the characteristic wet summers returned to eastern coastal regions in 2008 after a long drought. The value of hive losses attributable to SHB over the following three summers (2008-2011) in Queensland, Australia, was conservatively estimated at $\mathrm{A} \$ 8$ million (Lamb \& Leemon, 2011). 
Adult SHB are attracted to honeybee hives where they feed on unprotected bee brood, honey and pollen (Hood, 2004). It is the SHB larval stage which can cause extensive damage to hives and stored comb as they feed on bee brood and pollen stores (presumably as a nutritional source of protein) and leave behind waste. Fermentation of hive products has been associated with large numbers of SHB larvae and the yeast Kodamaea ohmeri (Etchells \& Bell) Yamada et al. (Ascomycota) has been isolated from both the fermenting hive material and all stages of the SHB life cycle (Torto et al., 2007b; Benda et al., 2008; Leemon, 2012). It is believed that this yeast is primarily responsible for the fermentation of hive products associated with larval development (Leemon, 2012). The resulting fermented honey (or 'slime') is rejected by honeybees and cannot be marketed by the beekeeper. Heavy larval infestations may also result in total hive collapse after the queen ceases to lay eggs and the colony absconds (Hepburn \& Radloff, 1998; Hood, 2004). Anecdotal observations in Queensland have noted that collapsed, 'slimed-out' hives are very attractive to adult SHB (DM Leemon, pers. obs.; P Warhurst, pers. comm.).

Work in the USA has shown that SHB are attracted to a range of hive odours, particularly the odour of adult worker bees and fermenting pollen dough, a hive product substitute (Suazo et al., 2003; Torto et al., 2005, 2007a; Nolan \& Hood, 2008). The aim of this study was to investigate the changes in volatile profiles of honeycomb and brood comb from different sources that have been altered by the action of developing SHB larvae and yeast, and explore changes in attractiveness of these hive products to SHB.

\section{Materials and methods}

\section{Hive products and beetles}

Honeycomb and capped brood comb used in this study were collected from three replicate apiaries at suburban Bellbowrie $\left(27.55^{\circ} \mathrm{S}, 152.89^{\circ} \mathrm{E}\right)$, rural Inglewood $\left(28.42^{\circ} \mathrm{S}\right.$, $\left.151.07^{\circ} \mathrm{E}\right)$ and peri-urban Moggill $\left(27.60^{\circ} \mathrm{S}, 152.86^{\circ} \mathrm{E}\right)$, in southeast Queensland, Australia. Single frames of honeycomb and brood comb were transported from each apiary to the laboratory and stored at $5{ }^{\circ} \mathrm{C}$ until use (less than $48 \mathrm{~h}$ ). Honeycomb and brood comb were allowed to reach room temperature before use.

Adult SHB used in the study were sourced from laboratory cultures maintained at the Ecosciences Precinct, Dutton Park, Queensland, as outlined in Cribb et al. (2013). The beetles were up to 3 weeks old and predominantly had no previous exposure to hive products before being used in attraction assays and cultures to generate slime.

\section{Slime production}

In this study, slime is fermenting hive-product, progressively altered by the action of SHBs and yeast over time, and was produced in the laboratory with beetle cultures using the respective hive products of each apiary and sampled fresh for assays as needed. Preliminary studies to optimize the development of SHB larvae and associated slime production in the laboratory were conducted using various combinations of adult $\mathrm{SHB}$ on honeycomb and brood comb. It was found that adult SHB did not breed on honeycomb alone (no evidence of eggs or larvae), whereas rapid larval development occurred with minimal slime production on brood comb alone. The best slime (with the highest yeast production) was obtained when a combination of honeycomb and brood comb was used (Figure 1). It is likely that these differences are due to availability of protein from the brood and pollen, an essential nutritional requirement for the development of insect larvae (Douglas \& Simpson, 2013).

Slime material was produced in the laboratory with the respective hive products of each apiary. On day 0 , four pieces of honeycomb and brood comb (ca. $90 \times 110 \mathrm{~mm}$ ) were weighed and placed in each of four opaque plastic bags $(190 \times 190 \mathrm{~mm})$ with $100 \mathrm{~mm}$ flaps. Approximately $3 \mathrm{ml}$ of tap water was sprayed into each bag, using an atomizer, to promote slime development. The bags were placed in separate transparent plastic containers $(195 \times 195 \times 210 \mathrm{~mm})$, and 40 mixed-sex SHB adults were put into each bag to breed. The containers were sealed with perforated plastic lids and incubated at $27{ }^{\circ} \mathrm{C}$ and $65 \%$ r.h. in darkness. The bag contents were sprayed with water $3 \times$ per week. On each of days $4,8,12$, and 18,10-ml samples of slime were taken from each bag, combined, and used in attraction assays and analysis by gas chromatography-mass spectrometry (GC-MS). Slime samples were also qualitatively examined for the presence of yeast under a compound light microscope. This process was repeated for hive products from each apiary. Samples from the Moggill apiary were allowed to continue until day 35 with the aim of investigating the point at which the

Table 1 Mean ( \pm SEM) mass (g) of honeycomb and brood comb pieces from each apiary used to generate slime

\begin{tabular}{lrr}
\hline Apiary & \multicolumn{1}{c}{ Brood comb } & \multicolumn{1}{c}{ Honeycomb } \\
\hline Bellbowrie & $143 \pm 2.68 \mathrm{a}$ & $429 \pm 16.9 \mathrm{a}$ \\
Inglewood & $110 \pm 2.42 \mathrm{~b}$ & $363.3 \pm 11.3 \mathrm{~b}$ \\
Moggill & $148.3 \pm 8.31 \mathrm{a}$ & $326.5 \pm 9.91 \mathrm{~b}$ \\
\hline
\end{tabular}

Means within a column followed by different letters are significantly different (Fisher's protected least significant difference test: $\mathrm{P}<0.05$ ). 

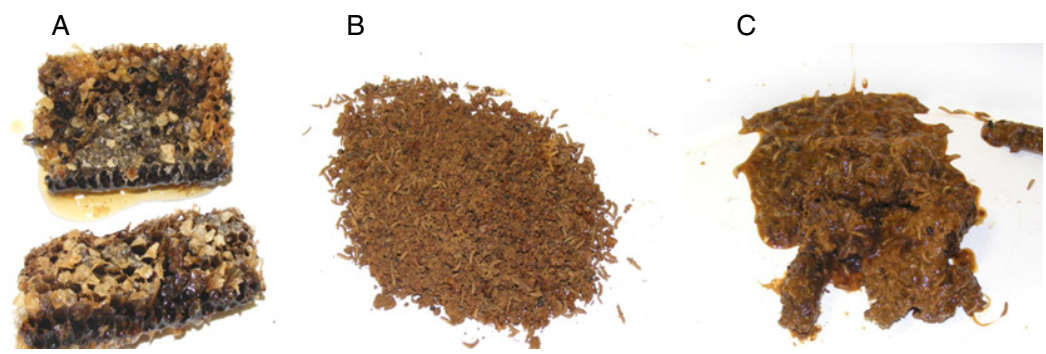

Figure 1 Small hive beetle (SHB) larval development on hive products 7 days after introduction of adult SHB. (A) No larvae or slime developed on honeycomb. (B) Brood comb only resulted in rapid larval development with some 'dry' slime. (C) A combination of honeycomb and brood comb resulted in larval development in a viscous thick slime.

volatiles were no longer attractive to adult SHB. Differences in initial mass of honeycomb and brood comb were assessed by ANOVA, with post-hoc comparisons using Fisher's protected least significant difference test (GenStat, V16.1.0.10916; VSN International, Hemel Hempstead, $\mathrm{UK})$.

\section{Gas chromatography-mass spectrometry analysis}

Volatile components of the headspace above samples from each replicate apiary were analysed to examine changes in these volatiles as samples aged. Laboratory air was pulled through a charcoal trap over the sample of slime, honeycomb or brood comb (ca. $5 \mathrm{ml}$ ), or an empty vial (blank) in a glass Erhlenmeyer flask $(250 \mathrm{ml})$ at a flow rate of $250 \mathrm{ml}$ per min for $18 \mathrm{~h}$. After passing over the sample, the air passed through a thermal desorption tube preloaded with Tenax TA (35/60 mesh), Carbograph 1TD (40/60 mesh) (344.6 $\pm 0.75 \mathrm{mg})$ (Markes International, Llantrisant, UK).

Samples were thermally desorbed from the tubes using a TD-100 thermal desorption unit (Markes International) and introduced into a GC (6890 Series; Agilent, Santa Clara, CA, USA) coupled to a MS (Agilent 5975) and fitted with a silica capillary column (Agilent, model HP5-MS, $30 \mathrm{~m} \times 250 \mathrm{~mm}$ i.d. $\times 0.25 \mu \mathrm{m}$ film thickness). Data were acquired under the following GC conditions: carrier gas $\mathrm{He}$ at $51 \mathrm{~cm} \mathrm{~s}^{-1}$, split ratio 13:1, transfer-line temperature $280{ }^{\circ} \mathrm{C}$, initial temperature $40{ }^{\circ} \mathrm{C}$, initial time $2 \mathrm{~min}$; rate $10^{\circ} \mathrm{C}$ per min, final temperature $260{ }^{\circ} \mathrm{C}$, final time $6 \mathrm{~min}$. The MS was held at $230^{\circ} \mathrm{C}$ in the ion source

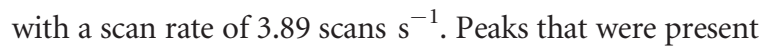
in blank (control) samples were discarded from analysis in test samples. Tentative identities were assigned to peaks with respect to the National Institute of Standards and Technology mass spectral library. Mass spectra of peaks from samples with the same retention time were compared to ensure that the compounds were the same. Identity of the major components was confirmed by injection of standards (Sigma-Aldrich, Castle Hill, NSW, Australia).
Differences in areas of individual compounds across time were assessed by ANOVA, with post hoc comparisons using Fisher's protected least significant difference test (GenStat, V16.1.0.10916; VSN International).

To determine whether there were statistically significant differences in the slime relating to number of days since inoculation with beetles, the data were compared by an analysis of similarity (ANOSIM) based on a Bray-Curtis similarity matrix. The ANOSIM tests are a range of Mantel-type permutations of randomization procedures, which make no distributional assumptions. These tests depend only on rank similarities, and thus are appropriate for these types of data. The software used for this multivariate analysis was Primer 5 for Windows (v. 5.2.9; Clarke \& Gorley, 2001). These analytical procedures have been used successfully in previous studies to statistically analyse chromatographic data (Hayes et al., 2006, 2013; Burgener et al., 2009; Nahrung et al., 2009).

\section{Attraction trials}

The comparative attractiveness of hive products to $\mathrm{SHB}$ was assayed $4 \times$ per apiary, using slime of ages $4,8,12$ and 18 days after inoculation with beetles. In each assay, four beetle traps containing either honeycomb, brood comb, slime, or nothing (control), were placed in each of six replicate cages $(60 \times 60 \times 60 \mathrm{~cm})$ made of white mesh and plastic (Bug Dorm insect tent 2120; Australian Entomological Supplies, Coorabell, NSW, Australia). Beetle traps were cylindrical plastic vials $(108 \times 44 \mathrm{~mm})$ with $50-\mathrm{mm}$ funnels made of fibre-glass insect-screen $(1 \times 0.5 \mathrm{~mm}$ pore size) inserted into their openings, allowing beetle entry but inhibiting exit. At the back of each trap was placed $5 \mathrm{ml}$ of a hive product, followed by a $30-\mathrm{mm}^{2}$ piece of cotton wool as a substrate for the hive product, and then a $150-\mathrm{mm}^{2}$ piece of crumpled paper towel for beetle harborage. Control traps contained cotton wool and paper towel only. Aluminium foil was wrapped around the bases and sides of the traps, to darken their interiors thus increasing their attractiveness to these negatively 
phototactic beetles. The traps were secured to the floor in the corners of the cages using Blu-Tack ${ }^{\mathrm{TM}}$ (Bostick, Thomastown, VIC, Australia) and were orientated diagonally with their openings facing towards the centre of the cage floor. The cages were then placed in a controlled environment room $\left(27{ }^{\circ} \mathrm{C}, 65 \%\right.$ r.h., and L13:D11 photoperiod). Forty unsexed SHB adults were released from unlidded 250-ml plastic jars placed on the floor in the centre of each cage. Beetles were allowed to roam in cages overnight for $17 \mathrm{~h}$ (16:00 to 09:00 hours, with $11 \mathrm{~h}$ darkness from 19:00 to $06: 00$ hours), after which the number of beetles in each trap was recorded. A Friedman's non-parametric ANOVA was used to determine whether attractiveness of the treatments differed. Pair-wise comparisons (Wilcoxon signed rank) were then used to determine where these differences lay. Analyses were performed with IBM SPSS Statistics v. 21 (IBM SPSS, Armonk, NY, USA).

\section{Results}

\section{Larval and slime development on hive products}

The mean mass of hive products used for development of slime from each apiary is shown in Table 1 . The mass of brood comb varied between apiaries, with a significantly smaller mass from the Inglewood apiary compared to the other sites. Honeycomb mass also varied between apiaries, with significantly heavier honeycomb from Bellbowrie compared to the other two sites (ANOVA: brood comb: $\mathrm{F}_{2,11}=15.72$; honeycomb: $\mathrm{F}_{2,11}=15.77$, both $\mathrm{P}<0.001)$.

The development of SHB larvae and associated breakdown of hive products to slime varied with respect to size of final instars between the four bags used for each batch of hive products from the three apiaries. It was assumed this reflected the natural variation that would occur in the field. Thus, samples from each bag were pooled for testing in both the attraction assays and GCMS analyses. There also appeared to be some variation in the development of SHB larvae on the hive products from the three sources. Qualitative microscopic examination of samples of the slime associated with the SHB larval development revealed that the concentration of yeast cells increased with time (data not shown).

\section{GC-MS analyses}

Representative chromatograms from the Moggill apiary, showing the compounds detected by GC-MS analysis in the headspace above fermenting hive products are shown (Figure 2). The chromatograms from the other two replicate apiaries were very similar. Identified compounds are typical compounds produced by yeast fermentation and include a variety of alcohols, aldehydes and acetates. There was a variety of compounds with similar carbon skeletons, particularly based on the propanol and butanol moieties.

As fermentation progressed there was a consistent increase in the number of compounds detected and in the amount of each compound (Figure 2). The odour profile became more complex through time, and for each component there was an increase in the concentration of that component, until a plateau was reached at about day 12 . There were, however, differences in the timing of volatile production, with the samples from the Inglewood apiary appearing to be slower to begin producing some compounds than samples from the other two apiaries.

Considering samples from all three apiaries, there was an overall statistically significant difference in samples and pair-wise comparisons demonstrated a shift in samples as time progressed (ANOSIM: Global $\mathrm{R}=0.321, \mathrm{P}=0.038$ ). Overall, samples from day 8 were not different to those from day 4 , but by day 12 they were statistically distinguishable. This difference persisted until day 18 , and is based not merely on the presence/absence of key components, but also on their abundance.

For all three apiaries, ethanol was a predominant peak in all samples examined. Moreover, the increase in the levels of ethanol through time was significant (ANOVA: $\mathrm{F}_{3,11}=7.42, \mathrm{P}=0.011$ ). Several other alcohols (e.g., isobutanol, isopentanol) were also detected in samples from all three apiaries. These compounds were not detected in the early samples; however, their concentrations increased as the trials progressed (Table 2).

\section{Attraction assays}

The volatiles emanating from the hive products as they were broken down by the action of SHB larvae and yeast were highly attractive to adult SHB and became more attractive with time (Figure 3 ). This coincided with a significant decrease in the relative attractiveness of brood comb and honeycomb [Friedman's non-parametric ANOVA: day $4: \chi^{2}=40.90$; day $8: \chi^{2}=39.20$; day 12 : $\chi^{2}=45.95$; day 18: $\chi^{2}=41.29$, all d.f. $=4, \mathrm{n}=90$, $\mathrm{P}<0.001$; Figure 3. Slime from the Moggill day-35 sample was also significantly more attractive than the other treatments $\left(\chi^{2}=17.21\right.$, d.f. $\left.\left.=4, \mathrm{P}=0.002 ; \mathrm{n}=30\right)\right]$.

The number of untrapped individuals was low across all trials (Figure 3 ) and in general was slightly higher in day-4 assays. Only 2-3 beetles were found untrapped on the other days. The highest proportion untrapped (mean \pm SEM $=0.26 \pm 0.025$ ) occurred on day 4 in the Bellbowrie trial and the lowest proportion $(0.00042 \pm 0.0002)$ on day 12 of the Moggill trial. Often untrapped SHB (alive and dead) were observed just outside or under traps; however, because these beetles had not yet made a choice to enter the trap they were recorded 

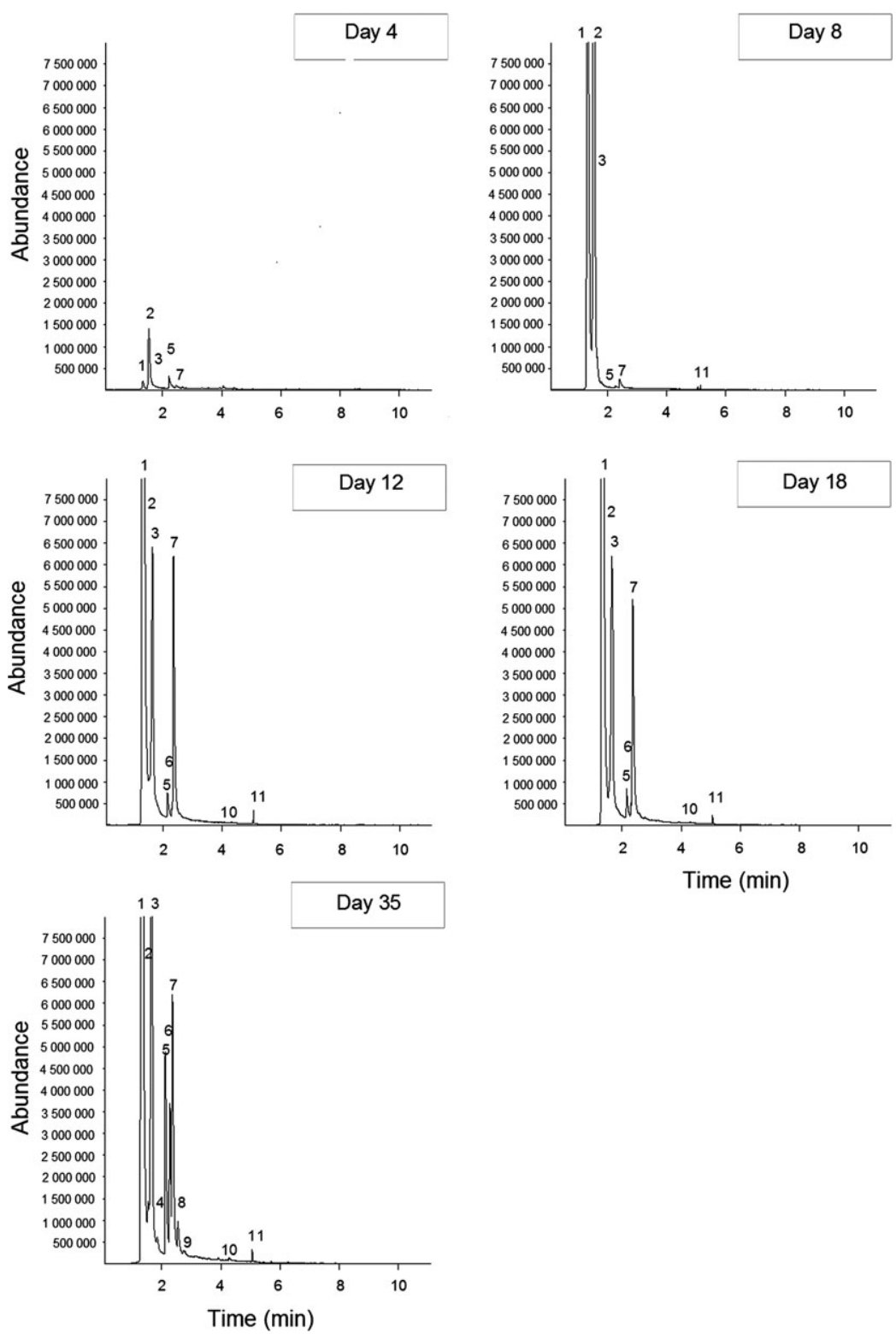

Figure 2 Total ion chromatogram traces showing the increase in complexity and development of components in fermenting hive product from the Moggill apiary through time. (1) Ethanol; (2) 2,3butadione; (3) isobutanol; (4) 1-butanol; (5) 3-hydroxy-2-butanone; (6) 2,4,5trimethyl-1,3-dioxolone; (7) isopentanol; (8) 3-methyl-2-heptanal; (9) 2-pentanol; (10) isopentyl acetate; (11) 5isothiazolylmethanol. as untrapped. A very low proportion of SHB was found in control traps, lacking any attractant materials $(<0.0002$ overall).

Overall, honeycomb was the least attractive hive material to SHB. The highest number of beetles attracted to the honeycomb occurred on day 4 , but as the slime became more attractive, the number attracted to honeycomb decreased. The brood comb was the most attractive hive product on day 4 for the Inglewood and Moggill trials; however, the relative attractiveness of the brood comb decreased over time as the attractiveness of the slime increased for all three trials. in general, the honeycomb sourced from the apiaries was homogeneous; however, the pieces of honeycomb from Bellbowrie used to generate slime were heavier than those from Inglewood or Moggill (Table 1). It was exceedingly difficult to get homogeneous pieces of brood within trials and across trials. The brood comb between apiaries differed in the amount and type of protein present (pollen, bee eggs, larvae, or pupae). We noted that the brood comb from Inglewood had less capped brood than that from the Bellbowrie and Moggill sources. This is reflected in the lower mass for pieces of brood comb of the same dimensions (Table 1). 
Table 2 Mean $\left( \pm\right.$ SEM) area $\left(\times 10^{6}\right)$ for compounds in fermenting hive products showing the increase in complexity and development of components through time

\begin{tabular}{llccc}
\hline & \multicolumn{2}{l}{ Days after addition } & & \\
\cline { 2 - 5 } Compound & 4 & 8 & 12 & 18 \\
\hline Ethanol & $7.22 \pm 2.26 \mathrm{a}$ & $266.8 \pm 189 \mathrm{ab}$ & $789.0 \pm 236 \mathrm{bc}$ & $1101.6 \pm 202.7 \mathrm{c}$ \\
2,3-Butadione & $29.7 \pm 23.1$ & $431.4 \pm 349$ & $12.9 \pm 5.70$ & $10.4 \pm 3.92$ \\
$\begin{array}{l}\text { Isobutanol } \\
\text { 1-Butanol }\end{array}$ & $2.15 \pm 1.02$ & $7.69 \pm 5.39$ & $111.3 \pm 95.1$ & $127.7 \pm 113.7$ \\
3-Hydroxy-2-butanone & 12.4 & & & 20.4 \\
2,4,5-Trimethyl-1,3-dioxolone & & 0.96 & 2.93 & 4.63 \\
$\begin{array}{l}\text { Isopentanol } \\
\text { 3-Methyl-3-heptanal }\end{array}$ & 2.78 & $3.71 \pm 2.83$ & $80.6 \pm 79.1$ & $62.5 \pm 61.1$ \\
2-Pentanol & & & 0.30 & $0.33 \pm 0.06$ \\
Isopentyl acetate & & & $1.01 \pm 0.77$ \\
5-Isothiazolylmethanol & & $0.28 \pm 0.19$ & $1.05 \pm 0.49$ \\
\hline
\end{tabular}

Means within a row followed by different letters are significantly different (Fisher's protected least significant difference test: $\mathrm{P}<0.05$ ).

Figure 3 Mean proportion (+ SEM) of small hive beetle adults attracted to each hive product as the slime ages. Different letters above columns indicate significant difference in mean proportions (Wilcoxon signed rank: $\mathrm{P}<0.05)$.

In all trials, the fermenting hive products became more attractive through time; however, the rate at which this increased varied across the trials. On day 4 the Bellbowrie slime was already more attractive than the honeycomb and by day 12 , most SHB $(0.88 \pm 0.03)$ entered the slime trap. The Moggill and Inglewood slimes became more attractive by day 12 . More variation was seen with the Moggill hive products. The slime attracted most beetles at day 12 $(0.83 \pm 0.02)$, but at day 18 the slime attracted fewer beetles $(0.59 \pm 0.07)$ because the relative attractiveness of the brood comb increased in two replicates $(0.38 \pm 0.06)$. The GC-MS analysis of these samples confirmed the presence of yeasty volatiles, especially ethanol, leading us to speculate that these particular brood comb samples were contaminated with yeast. This variation in results still supports the hypothesis that volatiles derived from the action of some yeasts on hive products are highly attractive to adult SHB.

The Moggill trial was run for extra time until day 35 to investigate the point at which the volatiles were no longer attractive to adult SHB. By day 35 it was noted that all larvae had left the bags of slime to pupate; however, the fermented slime samples were still highly attractive with an average proportion of $0.88 \pm 0.02$ beetles trapped.

\section{Discussion}

The increasing number of mixed-sex adult SHB entering the traps baited with slime associated with developing SHB larvae is strong evidence that SHB find the slime highly attractive and the volatile profile becomes more attractive with time as the chemical complexity of the 
ageing slime increases. There were no visual or tactile cues to distinguish between traps, and very few beetles made a random choice to enter a trap without odour attractant. These results strongly suggest the choice to enter a trap was directed by odour in this study.

Some beetles (both alive and dead) that were recorded as not trapped were found to be directly under the trap containers. These beetles may have been attracted to the volatiles in that trap but had not yet chosen to enter or had died nearby. This suggests that our estimates of trapping rate is conservative, as beetles attracted to a trap but which had not entered were recorded in the 'not trapped' group.

A key driver in the change of attractiveness through time is likely to have been ethanol, well-known to be attractive to insects from a variety of orders (Montgomery, 1983; Byers, 1992; Casana-Giner et al., 1999), including other members of the Nitidulidae (Bartelt \& Hossain, 2006). The levels of ethanol increased significantly through time, and may well explain at least the early increases in attraction. As the ethanol levels reached a plateau around day 12, further increases in attractiveness are likely to have been as a result of the increasing production of additional fermentation products. The compounds detected by the GC-MS analysis were typical compounds produced by yeast fermentation (Nout \& Bartelt, 1998), including a variety of alcohols, aldehydes and acetates. These types of fermentation products have been found to be highly attractive to the nitidulid beetle Carpophilus davidsoni Dobson (Bartelt \& Hossain, 2006).

The variability in the development of fermentation products, and the attractiveness to $\mathrm{SHB}$, correlates with differences in the amount of brood comb material available at the start of the study, and thus the amount and type of protein source available. This variation most likely accounted for the variation in rate of larval - and associated slime - development seen within and between trials. All insect larvae require protein for growth and development, therefore variation in protein can be expected to influence the rate of larval development (Douglas \& Simpson, 2013).

Comprehensive studies have reported aggregation pheromones used by species of Carpophilus beetles and their application in attract and kill traps. These pheromones are highly effective when combined with fermentation products. Blends of the key fermentation products were synergistic, and essential to maximize trap efficiency (Bartelt \& James, 1994; Bartelt \& Hossain, 2006, 2010; Hossain et al., 2008). It is possible that SHB (also of the Nitidulidae) may produce an aggregation pheromone that increased the number of beetles in the traps in this study, although we have no evidence for this. Torto et al. (2007b) reported that they were not able to demonstrate whether SHB produce either sex or aggregation pheromones during their studies; however, we believe this is still an area worth further investigation.

Many of the detected compounds (e.g., ethanol, isobutanol, isopentanol, isopentyl acetate) have previously been reported arising from either honeybees (Torto et al., 2005) or an artificial substance known as pollen dough, inoculated with the yeast K. ohmeri (Torto et al., 2007a). In both cases these compounds were shown to be attractive to SHB. Interestingly, one of the detected compounds is isopentyl acetate, a compound known since the 1960s as a honeybee alarm pheromone (Boch et al., 1962). This substance has been reported to elicit an electrophysiological response from SHB (Torto et al., 2007a), and it could be a key cue for beetles in their detection of a stressed hive.

The fermenting hive products known as slime are clearly more attractive to SHB than the unfermented hive products. Honeycomb has previously been shown to be highly attractive to SHB (Suazo et al., 2003), therefore it may well be that in the field these products will also be more attractive to incoming adult SHB than the hive. However, our studies have also demonstrated the inherent variation in the rate of production of these volatile mixes. We suggest that the volume and rate of emission of fermentation volatiles are affected by the level of protein and carbohydrate available in the hive for the initial SHB larval development; this in turn probably influences the development of the yeast driving the fermentation. Such levels will vary throughout the year and may also be influenced by the local flowering vegetation. In addition, the number of SHB larvae present, as well as abiotic conditions such as temperature and humidity, will also affect the development of the attractive volatiles.

This study is the first to report the development of SHBattracting volatiles from honeycomb and brood comb from honeybee hives that have been infected with SHB. It builds on previous studies which investigated the volatiles emanating from SHB-conditioned pollen dough, a mixture of harvested pollen and honey (Arbogast et al., 2007, 2009; Torto et al., 2007a). In using natural hive materials we were able to produce a similar mix of SHB-attracting volatiles for which the attractiveness persisted for much longer than in previous reports (Torto et al., 2007a). The use of brood comb and honeycomb more closely replicated the observations of adult SHB attraction to 'slimed up', collapsed hives infested with heavy burdens of SHB larvae (DM Leemon, unpubl.).

A pilot study (RA Hayes, BA Amos, SJ Rice \& DM Leemon, unpubl.) was conducted to test the attractiveness of the fermenting hive products in the field. Traps (Unitrap, AlphaScents) were located at two European honeybee apiaries, three Australian native bee [Tetragonula carbonaria (Smith)] hive locations, and at three urban locations well 
away from any known managed hives. All traps were located in the shade, ca. $50 \mathrm{~cm}$ from the ground, and within $3 \mathrm{~m}$ of a hive (if appropriate) and were assessed after 2 weeks in early January 2015. Aethina tumida adults were trapped at both apiaries, at two of the three urban sites, and one of the three native bee hive sites. The aim of this study was to inform the design of future field trials.

The enormous potential for variation in natural products will limit their use in attractant traps for SHB. However, suitable blends of synthetic compounds based on selected fermentation volatiles show potential for a lure with minimal variation, suitable for deployment in an effective out-of-hive trap for this pest. Previous studies on developing a similar system for another nitidulid beetle have demonstrated the length of time such research can take, but still producing a successful outcome (Bartelt \& James, 1994; Bartelt \& Hossain, 2006, 2010; Hossain et al., 2008). The present study forms the basis for further work in which synthetic blends of key volatiles can be developed and tested for attractiveness to SHB, to develop a lure suitable for an external SHB trap.

\section{Acknowledgements}

The authors are very grateful to George Pallot and Wayne Sawdy for providing hive materials (Moggill and Inglewood, respectively), and to Dr Helen Nahrung (University of the Sunshine Coast) for help and discussions regarding the statistical analyses. The manuscript was greatly improved by suggestions from Dr Manon Griffiths (DAFF-Q) who read an earlier draft.

\section{References}

Arbogast RT, Torto B, Van Engelsdorp D \& Teal PEA (2007) An effective trap and bait combination for monitoring the small hive beetle, Aethina tumida (Coleoptera: Nitidulidae). Florida Entomologist 90: 404-406.

Arbogast RT, Torto B \& Teal PEA (2009) Monitoring the small hive beetle Aethina tumida (Coleoptera: Nitidulidae) with baited flight traps: effect of distance from bee hives and shade on the numbers of beetles captured. Florida Entomologist 92: 165-166.

Bartelt RJ \& Hossain MS (2006) Development of synthetic foodrelated attractant for Carpophilus davidsoni and its effectiveness in the stone fruit orchards in southern Australia. Journal of Chemical Ecology 32: 2145-2162.

Bartelt RJ \& Hossain MS (2010) Chemical ecology of Carpophilus sap beetles (Coleoptera: Nitidulidae) and development of an environmentally friendly method of crop protection. Terrestrial Arthropod Reviews 3: 29-61.

Bartelt RJ \& James DG (1994) Aggregation pheromone of Australian sap beetle, Carpophilus davidsoni (Coleoptera: Nitidulidae). Journal of Chemical Ecology 20: 3207-3219.
Benda ND, Boucias D, Torto B \& Teal P (2008) Detection and characterization of Kodamaea ohmeri associated with small hive beetle Aethina tumida infesting honey bee hives. Journal of Apicultural Research 47: 194-201.

Boch R, Shearer DA \& Stone BC (1962) Identification of iso-amyl acetate as an active component in the sting pheromone of the honey bee. Nature 195: 1018-1020.

Burgener N, Dehnhard M, Hofer H \& East ML (2009) Does anal gland scent signal identity in the spotted hyaena? Animal Behaviour 77: 707-715.

Byers JA (1992) Attraction of bark beetles, Tomicus piniperda, $\mathrm{Hy}$ lurgops palliatus, and Trypodendron domesticum and other insects to short chain alcohols and monoterpenes. Journal of Chemical Ecology 18: 2385-2402.

Casana-Giner V, Gandia-Balaguer A \& Primo-Yufera E (1999) Field trial of an attractant mixture for dipterous, including the pest Ceratitis capitata (Wiedemann) (Dipt., Tephritidae), in Valencia, Spain. Journal of Applied Entomology 123: 47-48.

Clarke KR \& Gorley RN (2001) PRIMER v5: User Manual/Tutorial. PRIMER-E, Plymouth, UK.

Clay H (2006) Small hive beetle in Canada. Hivelights 19: 14-16.

Cribb BW, Rice SJ \& Leemon DM (2013) Aiming for the management of the small hive beetle, Aethina tumida, using relative humidity and diatomaceous earth. Apidologie 44: 241-253.

Douglas AE \& Simpson SJ (2013) Nutrition. The Insects: Structure and Function (ed. by RF Chapman, SJ Simpson \& AE Douglas), pp. 81-106. Cambridge University Press, Cambridge, UK.

Ellis JD \& Hepburn HR (2006) An ecological digest of the small hive beetle (Aethina tumida) a symbiont in honey bee colonies (Apis mellifera). Insectes sociaux 53: 8-19.

Elzen PJ, Baxter JR, Westervelt D, Randall C, Delaplane KS et al. (1999) Field control and biology studies of a new pest species, Aethina tumida Murray (Coleoptera, Nitidulidae), attacking European honey bees in the Western Hemisphere. Apidologie 30: 361-366.

Gillespie P, Staples J, King C, Fletcher MJ \& Dominiak BC (2003) Small hive beetle, Aethina tumida (Murray) (Coleoptera: Nitidulidae) in New South Wales. General and Applied Entomology 32: 5-7.

Hassan AR \& Neumann P (2008) A survey for the small hive beetle in Egypt. Journal of Apicultural Research 47: 186-187.

Hayes RA, Morelli TL \& Wright PC (2006) Volatile components of lemur scent secretions vary throughout the year. American Journal of Primatology 68: 1202-1207.

Hayes RA, Nahrung HF \& Lee DJ (2013) Consequences of Corymbia (Myrtaceae) hybridisation on leaf-oil profiles. Australian Journal of Botany 61: 52-59.

Hepburn HR \& Radloff SE (1998) Honey Bees of Africa. Springer, Berlin, Germany.

Hood WM (2004) The small hive beetle, Aethina tumida: a review. Bee World 85: 51-59.

Hossain MS, Bartelt RJ, Hossain MABM, Williams DG \& Chandra S (2008) Longevity of pheromone and co-attractant lures used in attract-and-kill stations for control of Carpophilus spp. Entomologia Experimentalis et Applicata 129: 148-156. 
Lamb H \& Leemon DM (2011) Small Hive Beetle Damage to Queensland Apiaries. Apimondia, Buenos Aires, Argentina.

Leemon DM (2012) In-hive Fungal Biocontrol of Small Hive Beetle. Rural Industries Research and Development Council, Canberra, Australia.

Lundie AE (1940) The Small Hive Beetle, Aethina tumida. Scientific Bulletin 220. Department of Agriculture and Forestry, Pretoria, South Africa.

Montgomery ME (1983) Ethanol and other host-derived volatiles as attractants to beetles that bore into hardwoods. Journal of Chemical Ecology 9: 181-190.

Mostafa AM \& Williams RN (2002) New record of the small hive beetle in Egypt and notes on its distribution and control. Bee World 83: 99-108.

Murray A (1867) List of Coleoptera received from Old Calabar. Annals and Magazine of Natural History London 19: $167-179$.

Nahrung HF, Waugh R \& Hayes RA (2009) Corymbia species and hybrids: chemical and physical foliar attributes and implications for herbivory. Journal of Chemical Ecology 35: 10431053.

Neumann P \& Elzen PJ (2004) The biology of the small hive beetle (Aethina tumida, Coleoptera: Nitidulidae): gaps in our knowledge of an invasive species. Apidologie 35: 229-247.

Neumann P, Hoffmann D, Duncan M \& Spooner-Hart R (2010) High and rapid infestation of isolated commercial honey bee colonies with small hive beetles in Australia. Journal of Apicultural Research 49: 343-344.
Nolan MP \& Hood WM (2008) Comparison of two attractants to small hive beetles, Aethina tumida, in honey bee colonies. Journal of Apicultural Research 47: 229-233.

Nout MJR \& Bartelt RJ (1998) Attraction of a flying nitidulid (Carpophilus humeralis) to volatiles produced by yeasts grown on sweet corn and a corn-based medium. Journal of Chemical Ecology 24: 1217-1239.

Ritter W (2004) Beutenkäfer in Portugal. Deutsches Bienen Journal 12: 14.

Somerville D (2003) Study of the Small Hive Beetle in the USA. Rural Industries Research and Development Council, Canberra, Australia.

Suazo A, Torto B, Teal PEA \& Tumlinson JH (2003) Response of the small hive beetle (Aethina tumida) to honey bee (Apis mellifera) and beehive-produced volatiles. Apidologie 34: 525-533.

Torto B, Suazo A, Alborn H, Tumlinson JH \& Teal PEA (2005) Response of the small hive beetle (Aethina tumida) to a blend of chemicals identified from honeybee (Apis mellifera) volatiles. Apidologie 36: 523-532.

Torto B, Arbogast RT, Alborn H, Suazo A, van Engelsdorp D et al. (2007a) Composition of volatiles from fermenting pollen dough and attractiveness to the small hive beetle Aethina tumida, a parasite of the honeybee Apis mellifera. Apidologie 38: 380-389.

Torto B, Boucias DG, Arbogast RT, Tumlinson JH \& Teal PEA (2007b) Multitrophic interaction facilitates parasite-host relationship between an invasive beetle and the honey bee. Proceedings of the National Academy of Sciences of the USA 104: 8374-8378. 